\title{
Assessment, Monitoring and Evaluation of Climate Smart Agriculture: A Review
}

\author{
Ibsa Dawid Mume \\ Oromia Agricultural Research Institute, Asella Agricultural Engineering Research Center, Socio-Economics Research Team, P. O. \\ Box 06, Asella, Arsi Zone of the Oromia Region, Ethiopia.
}

How to cite this paper: Ibsa Dawid Mume. (2021) Assessment, Monitoring and Evaluation of Climate Smart Agriculture: A Review. International Journal of Food Science and Agriculture, 5(3), 510-518.

DOI: $10.26855 / \mathrm{ijfsa} 2021.09 .022$

Received: July 18, 2021

Accepted: August 15, 2021

Published: September 3, 2021

*Corresponding author: Ibsa Dawid Mume, Oromia Agricultural Research Institute, Asella Agricultural Engineering Research Center, Socio-Economics Research Team, P. O. Box 06, Asella, Arsi Zone of the Oromia Region, Ethiopia.

Email: dawidibsa33@gmail.com

\begin{abstract}
This review expressions on assessment, monitoring and evaluation summaries that are necessary for the successful adoption of climate-smart agriculture (CSA). Concentration is placed mainly at the subnational and national levels. The review presents an overview of important climate change-related assessment, monitoring and evaluation activities in policy and programme processes and project cycles. The purposes was review how to conduct assessments for climate smart agriculture (CSA) policy and project design, how to implement monitoring and evaluation for climate smart agriculture programme and projects, the importance of monitoring and evaluation for climate-smart agriculture, the challenges and guiding principles baselines, and related concepts are also described. Monitoring and evaluation are initiated during the project preparation stage of the project cycle and are closely linked with the overall climate smart agriculture planning. Monitoring tracks progress, checks intermediate results, and informs adjustments during the project implementation. Evaluation deals primarily with the assessment of the results and impacts of CSA interventions. Details are provided about how to conduct assessments relating to policies and project justification and design, as well as monitoring and evaluation. In the last section, the specific challenges to assessment, monitoring and evaluation in the context of climate smart agriculture were reviewed and some guiding principles for addressing them are offered.
\end{abstract}

\section{Keywords}

Assessment, Monitoring and Evaluation, Climate Smart Agriculture, Climate Change, Challenges

\section{Introduction}

The Climate Smart Agriculture concept includes three goals: sustainably increase agricultural productivity and income as well as ensure food security; adapt to climate change and foster resilience to natural resources pressure; and contribute to the reduction or removal of greenhouse gas (GHG) emissions of agriculture, forestry, fisheries and aquaculture [1]. Especially in developing countries, agriculture still often accounts for more than 30\% of GDP [2]. Consequently, because of the many implications it has in different socio-economic and ecological spheres, it can play a pivotal role in achieving the 2030 Agenda for Sustainable Development [3]. A multitude of disciplines have implications with the agriculture sector [4], and obviously benefit from a general societal increasing concern regarding social and environmental sustainability, as this can translate into commitments both in the public and private sectors supporting their fields of expertise.

Given the inter linkages between CSA and the Sustainable Development Goals, it is important to assess the contribution of CSA to achieve the SDGs in order to inform decision-makers on the synergies or potential trade-offs of investments in CSA. Implementing the three pillars of CSA entails different consequences on different SDGs [5]. These 
trade-offs are often unavoidable, and policymakers are confronted with the challenge of finding a compromise [1], which is one of the reasons why it is important to have suitable and accurate guidelines to measure and monitor CSA and its effects on the Sustainable Development Goals. Monitoring and Evaluation is an important tool for enhancing farmers' practices. They consider it an unavoidable process of their work methodology, yet they often lack time and financial resources to implement thorough monitoring and evaluation practices [6].

Therefore, it is initiated to review assessment, monitoring and evaluation (M\&E) of climate smart agriculture. This review will help for assessing the monitoring and evaluation on climate smart agriculture for improvement of climate change in the past, present and future in the agriculture. The general objective of this review is to Assessing, Monitoring and Evaluation of Climate Smart Agriculture, with the specific objectives:

$\checkmark \quad$ To review how to conduct assessments for CSA policy and project design

$\checkmark \quad$ To review how to implement monitoring and evaluation for CSA programme and projects

$\checkmark \quad$ To review the importance of monitoring and evaluation for climate-smart agriculture

$\checkmark \quad$ To review challenges and guiding principles

\section{Literature Review}

\subsection{Defining Assessment, Monitoring and Evaluation for Climate Smart Agriculture: Scope, Purposes, Frameworks and Concepts}

The overall goal of assessments and monitoring and evaluation activities is to effectively guide the transition of sound climate-smart agriculture policies into climate-smart agriculture programme that are successfully applied on the ground. Climate change is likely to have the most severe impacts on groups that are already coping with food insecurity and vulnerable to shocks. Interventions must focus on understanding and addressing the needs and aspirations of these groups and ensure that they are included in decision-making processes. Monitoring and evaluation are not divisible, but they are two distinct activities. They need to be linked to understand causes and effects of different actions. Both are concerned, to different degrees, with tracking progress and change. Assessments for policy and project design usually take place ex-ante. They are conducted mainly in the conceptualization and preparation steps of planning. Climate impact assessments, climate-smart agriculture options appraisals and baseline projections are illustrated in Figure 1 bellow.

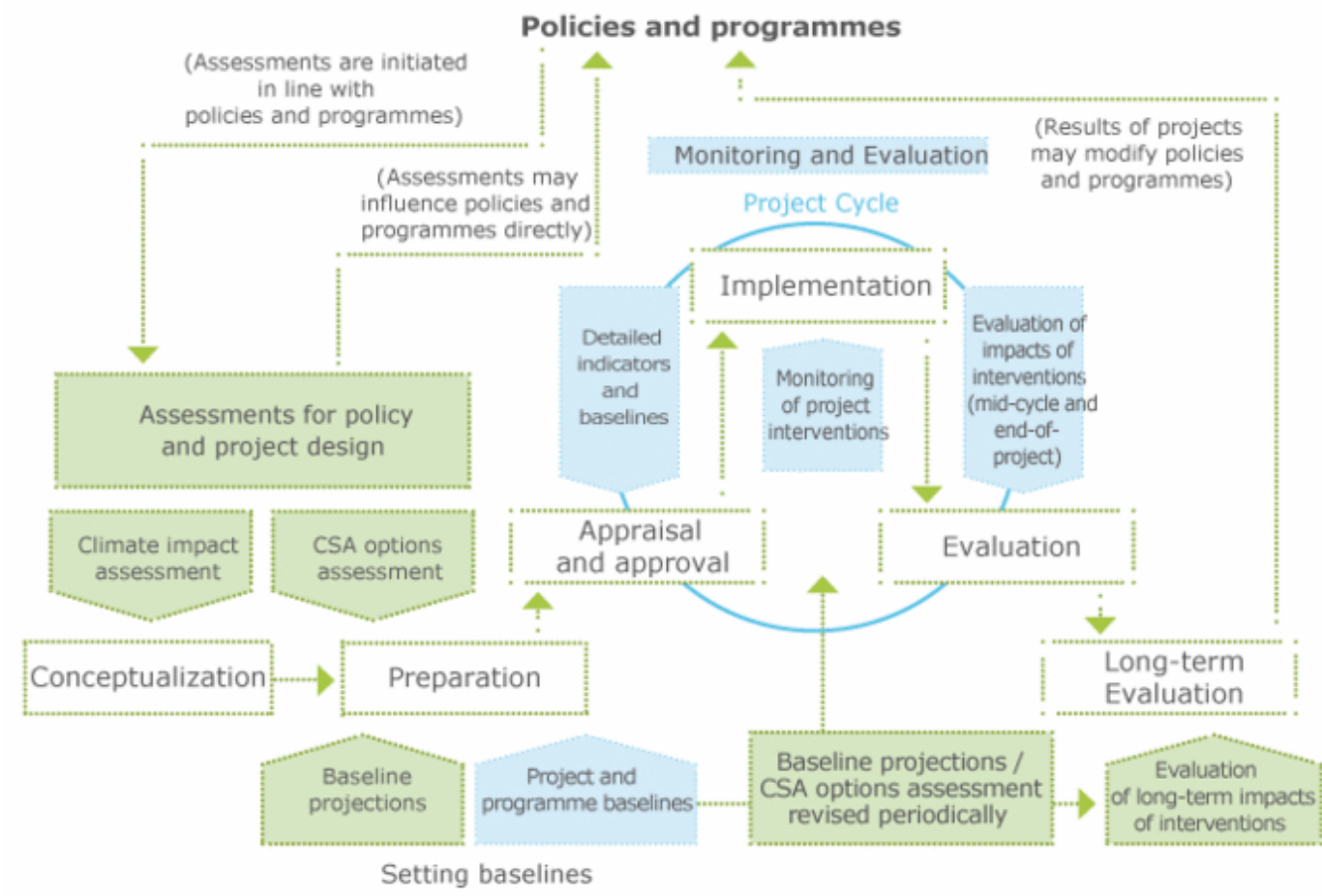

Assessments for policy and project design (green background) and monitoring and evaluation (blue background) are color coded respectively.

Figure 1. The scope of assessment, monitoring and evaluation for Climate Smart Agriculture within a project cycle and broader policies and programmes. 


\subsubsection{Assessments for Climate Smart Agriculture Policy and Project Design}

Assessments for policy and project design identify the impact of climate change and climate variability on the agricultural sector, food security and livelihoods. Climate impact assessments characterize the effects of climate change and identify the most vulnerable locations and contexts that require adaptation actions. Climate impact assessments are typically conducted at the project's conceptualization stage, but they are also used to inform policy directly (Figure 1), a type of strategic planning. The main elements of climate impact assessment are an assessment of changes in climate (historical, current, and projected future); an assessment of impacts of climate on agriculture; and an assessment of the vulnerability of livelihoods, including food security, to climate change. The relationship between climate and agriculture now and in the past can be combined with future climate projections to infer associated potential impacts on agriculture.

\subsubsection{Climate Impact Assessment}

Impact' refers to the effects of climate change on natural and anthropogenic systems. In the case of CSA, the impact will be felt in a variety of areas, including: landscapes, ecosystems, watersheds, infrastructure, farms, agricultural production and markets. Climate impact assessments specify the changes in climate in a historic, current or future context, and establish evidence-based relationships between climate and productivity in the agriculture, forestry and fishery sectors. Climate impact assessments indicate the vulnerability of different stakeholders to a changing climate and the potential impacts of climate change on agriculture. Stakeholders targeted by vulnerability assessments include male and female smallholder farmers, landless laborers, commercial farmers and people working in the value chain.

'Vulnerability' is frequently defined as a function of potential impacts (exposure and sensitivity to exposure) and adaptive capacity [7]. Exposure is the extent to which the system is physically harmed by climate change. Sensitivity is how affected a system is after the exposure. Adaptive capacity is the system's ability to avoid potential damages, take advantage of opportunities, and cope with the consequences of damages.

'Resilience' is the ability of a system and its component parts to anticipate, absorb, accommodate, or recover from the effects of a hazardous event in a timely and efficient manner [8]. A system may be made more resilient in a number of ways, including: managing human and environmental components of a system in a manner that maintains the system's status quo (e.g. managing water resources to better cope with drought); or transforming into a new system when the current system becomes untenable (e.g. eliminating irrigation and agricultural production if drought risk is too extreme) [9-12].

\subsubsection{Climate Smart Agriculture Options Assessment}

Following climate impact assessments, CSA options assessments examine the extent to which different CSA measures may achieve the objectives of increasing productivity, enhancing climate change adaptation and mitigation, and improving food security, given the expected impacts of climate change.

Examples of assessed benefits of CSA practices in contributing to climate change adaptation and mitigation, and food security

- Reduced soil erosion and minimum tillage, cover crops and improved rotations;

- Improved water availability from soil and water conservation activities;

- Improved crop yield with new varieties, a change in farm management;

- Improved livestock productivity through enhanced breeding and feeding practices;

- Balance among improved productivity, market prices, and farm income;

- Improved economic resilience from income diversification; and

- Reduced GHG emissions or increased soil carbon sequestration.

\subsubsection{Baselines and Baseline Projections}

Based on climate impact assessments, baseline projections can be developed for expected future climate variations, associated variations in agricultural outputs and respective vulnerabilities. These are projections of the state of climate impacts, agriculture, and food security and vulnerability without the programme or project's interventions. This 'without intervention' scenario helps to frame broader policies and programmes. Baseline projections provide 'counterfactuals' and are used to evaluate long-term impacts of CSA and related interventions at a longer time scale than typical development projects. However, in a situation of complexity that climate change creates, the baseline can keep shifting. Climate impact predictions are just that—predictions—and they may not come true. 


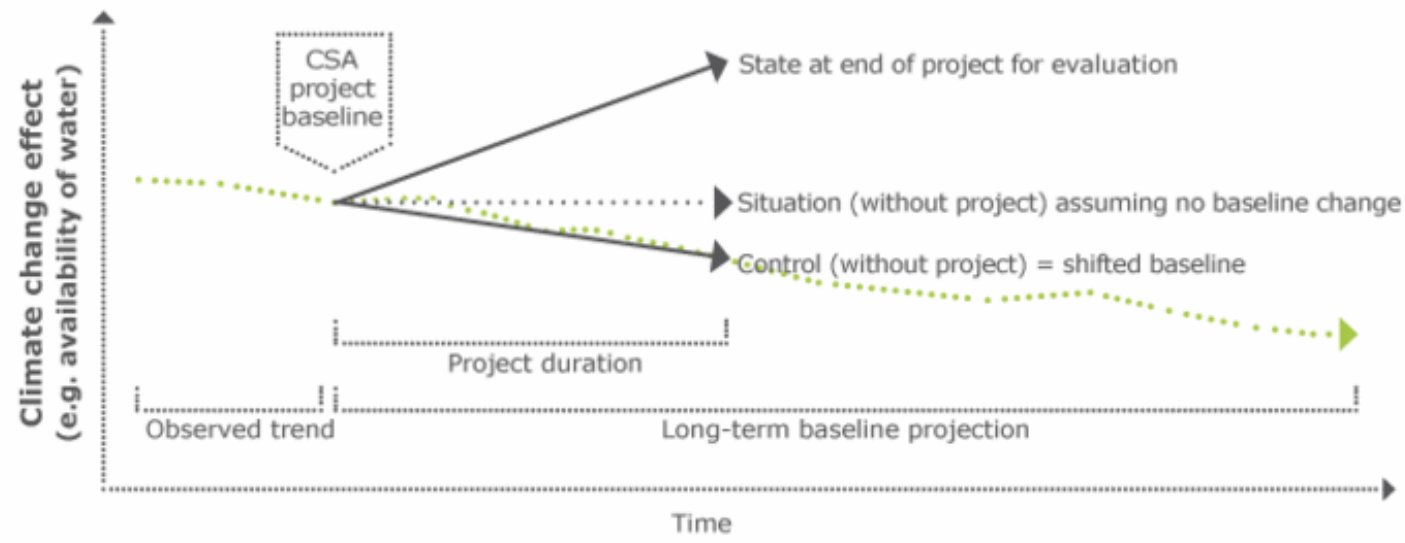

Figure 2. Baselines and baseline projections.

Over a short period, changes in baselines or baseline projections can be subtle, so they are not a great concern for shorter CSA projects [13].

\subsection{How to Conduct Assessments for CSA Policy and Project Design}

\subsubsection{Designing Assessments}

Abundant information on climate change and its impact on agriculture are available at global and regional scales. Information at national and subnational scales is more scarce but can be found from a range of sources, including: the Intergovernmental Panel on Climate Change (IPCC) Fourth Assessment Reports; the IPCC Special Report on Managing the Risks of Extreme Events and Disasters to Advance Climate Change Adaptation [8]. The major steps for designing assessments can be summarized as:

- Literature review;

- Identification of stakeholders;

- Assessment of information needs of stakeholders;

- Evaluation of role and capacity of stakeholders; and

- Design of assessments, including agreement on CSA objectives by stakeholders.

\subsubsection{Conducting Assessments}

Once the study design is drawn up in consultation with stakeholders, choices can be made about the data, methods and tools that best meet the specified spatial and temporal scales and the other requirements of the assessments. A variety of methods, tools and databases for climate data, climate downscaling tools and vulnerability assessment tools are described in [14-18]. CSA planners should choose a method that suits the needs of the project and programme. There is no single method that is applicable to all CSA projects.

\subsection{How to Implement Monitoring and Evaluation for CSA Programmes and Projects}

\subsubsection{Basic Overview of the Planning, Monitoring, Evaluation and Learning Cycle with in a Climate Smart} Agriculture Programme.

For CSA, as in any other development context, monitoring and evaluation cannot be seen as separate from the programme and project planning cycle processes that define objectives and intervention actions that focus on expected results. Evaluation primarily deals with the assessment of results and impacts.

A number of manuals and e-learning tools are available for in-depth monitoring and evaluation that can be applied to CSA interventions. Examples include the International Fund for Agricultural Development (IFAD) Monitoring and Evaluation Guide [19]. World Bank’s monitoring and evaluation tools and approaches, with basic definitions provided by the Organization for Economic Cooperation and Development, Development Assistance Committee (OECD DAC) [20]; and the European Commission Project Cycle Management.

\subsubsection{The Steps in Monitoring and Evaluation of Programmes and Projects with CSA Considerations}

As illustrious above, monitoring and evaluation start with the design process and identification of objectives. They cannot be seen as separate activities. Before telling monitoring and evaluation indicators and tools, some important design processes need to be described. A shared process for setting objectives and defining indicators among intervention stakeholders is a key to obtaining feedback, learning and planning, all of which are vital for CSA, which is quickly evolving. 


\subsubsection{Developing Indicators}

To measure project progress and achievements, it is necessary to identify suitable indicators and clarify related baselines, targets and means of verification for each of the results at different levels. Indicators are extensively treated in monitoring and evaluation guides. Highlighted below are some key aspects of indicators in relation to climate change $[21,22]$

\section{Characteristics of Indicators}

Indicators should, wherever possible, be Simple, Measurable, Attributable, Reliable and Time bound (SMART). The somewhat expanded set of SMART criteria presented below provides a useful guide for identifying appropriate indicators (modified from CIDA, cited in [13] :

1. Validity:

2. Precise and specific meaning:

3. Practical, affordable, and simple:

4. Reliability:

5. Sensitivity:

6. Clear direction, Utility, and owned.

\section{Typology of Indicators}

Using a simplified typology, indicators can be classified into four types. The four types of indicators are:

- Quantitative;

- Qualitative;

- Proxy indicators, andIndices.

\section{Range of Indicators}

Indicators for monitoring and evaluating projects' impact should try to reflect the objectives of climate smart agriculture. Some examples include:

- Agricultural outputs in the project area over a multiyear period [23];

- monitoring changes in land use on a wider scale, which can draw on literature such as sustainable land management impact monitoring;

- Resilience to flood and drought disasters over a multiyear period;

- Total extent of annual GHG emissions reduced from the project areas over a multiyear;

- Food security rate by household.

\subsubsection{Methods for Project Monitoring and Evaluation}

Methods for measuring results of outcomes and impacts (mainly evaluation) and progress against expected targets (mainly monitoring) are very large topics that are best examined in relation to literature on specific indicators.

\section{Methods for Project Monitoring}

Monitoring is a continuous or periodic process in which data on specific indicators are systematically collected to provide information about performance of a project. It needs to have in-built and integrated systems for tracking financial transactions, expected outputs, activity targets and achievements. Basic methods and tools for monitoring are:

$\checkmark$ Regular project monitoring involves the gathering of activity and output progress data, financial management information, and signaling emerging issues or good practices.

$\checkmark \quad$ Management information systems are web-based support systems that are increasingly being managed through remote devices, linked to financial management (FMS) and geographic information (GIS) systems.

$\checkmark$ Agriculture and natural resource management monitoring is carried out at frequencies and scales significant enough to provide meaningful information.

$\checkmark$ Process monitoring is often done to support regular monitoring, assess project process and institutional changes and relationships, and rapidly identify management responses.

$\checkmark \quad$ Participatory monitoring and evaluation methods include a wide range of methods for enhancing the engagement of the communities involved in programmes and projects.

\section{Methods for Evaluation}

Evaluation is a systematic and objective feedback of a completed or ongoing action, aimed at providing information about design, implementation and performance.

Evaluation, at key milestones in the programme, but especially at its conclusion or after its completion, involves gathering specific data relating to project indicators, and focuses on outcomes and impacts. It is important to revisit these indicators using the same methods for collecting data and information that were employed in the baselines assessments. However, evaluation is not only about the impact evaluation surveys. It also assesses the ongoing relevance of the de- 
sign, objectives and implementation mechanisms; reviews the efficiency, performance of different actors; and highlights lessons learned.

\subsection{Importance of Monitoring and Evaluation for Climate-Smart Agriculture Programmes and Projects}

Monitoring and evaluation are critical for ensuring climate-smart agriculture interventions are implemented properly and achieve the desired outcomes. Evaluations can also identify shortcomings and lessons for future policies and programmes. During the implementation stage, it is essential to monitor progress and identify successes and problems in climate-smart agriculture interventions, be they pilot initiatives, projects or programmes.

Effective monitoring and evaluation, which helps improve the design of future climate-smart agriculture interventions and stakeholders' decision-making, are part of a long-term learning process. Evaluations of programmes and projects that set out to strengthen climate-smart agriculture practices should contribute to expanding the knowledge base and deepen the scientific basis for climate-smart agriculture. An example of this type of contribution can be found in the syntheses analyses of large numbers of studies that has been done by the CGIAR Research Program on Climate Change, Agriculture and Food Security [24].

\subsection{Challenges and Principles in Monitoring and Evaluation}

Many challenges and principles need to be considered in assessment, monitoring and evaluation for agricultural development projects and programmes. CSA poses unique challenges for assessments, monitoring and evaluation. Most of the challenges and principles are common to assessments for policy and project design, as well as monitoring and evaluation.

\subsubsection{Definitions and Goals of in Monitoring and Evaluation}

"Climate-smart agriculture" is an evolving concept and there is not yet a single definition for it that is agreed by the international community. CSA means different things to different countries, depending for example on the level of agricultural development. In some cases, more focus is placed on mitigation, while in others the focus is mainly on increasing productivity and enhancing resilience. Likewise, there are differing views on how to define "adaptation" to climate change, or what constitutes "successful adaptation" to climate change. The lack of consensus indicates a lack of agreed metrics to determine effectiveness of activities to achieve CSA/adaptation, which means extra challenges to monitoring and evaluation [25-27, 13].

\subsubsection{Multi-Sectoral Issues and Engaging Stakeholders}

Climate change objectives link together various sectors and stakeholders, and as an evolving concept, CSA requires continuing even further dialogue and engagement of key players. CSA will not be successful unless relevant stakeholders are engaged at all levels and across all relevant sectors [25-27, 13]. The stakeholders to be consulted vary from the public level to the global level [25].

\subsubsection{Situating Monitoring and Evaluation within a Broader Development Perspective}

To avoid replication, monitoring and evaluation systems should be built on and integrated into existing systems, programmes and projects for agriculture, climate-responsible development and disaster risk reduction [25, 13]. According to the report of [28], within agricultural and rural development projects, there are already many actions, expected results and indicators that incorporate info on climate change actions and outcomes, or that can be enhanced by climate-smart agriculture actions with relatively lower costs.

\subsubsection{Scales, Leakage, Permanency, Externality and Ancillary Impact}

The issue of leakages and permanency is important for the monitoring and evaluation of climate change mitigation. Permanency refers to the principle that emission reductions represented by an offset should be maintained over time. In some cases, abandoning a climate-smart agriculture practice after only a few years will counterbalance the emissions previously avoided, and sometimes it may even surpass the emissions abated. This is why frequent monitoring is required to take into account such risks. Leakage refers to a situation where the emissions abatement that has achieved in one location is offset by increased emissions in unregulated locations.

According to [25, 27], a measure adopted for climate-smart agriculture may bring short-term benefits, while the same measure may lead to maladaptation over the long term and vice versa. The timing of monitoring and evaluation needs to be chosen to address both short- and long-term impacts. Different targets may be set for different time scales. Considering pathways for implementing climate-smart agriculture at different time scales will help improve the design of monitoring and evaluation systems. Institutions should have adequate systems for storing and retrieving information to support monitoring and evaluation [29, 25]. Accounting for externalities and ancillary impacts should also be considered, even if they are far more difficult to evaluate than the abatement of greenhouse gases or improvements in adap- 
tive capacities.

\subsubsection{Availability of Data and Information}

All assessment, monitoring and evaluation activities require data on a range of subjects, including climate, agriculture, socio-economic conditions, capacities and livelihoods. The quality of data directly affects the quality of assessment, monitoring and evaluation. Analyses based on poor quality data are of very limited value.

To characterize current and historical impacts of climate change on agriculture for the assessment purposes for policy and project design, good quality, continuous and long-term climate data are necessary (e.g., temperature, rainfall, wind, solar radiation, humidity, evaporation and runoff). Along with climate data, agricultural statistics describing the state of agriculture are necessary for the same time span. Such data includes crop yields and areas under cultivation, as well as fish and wood production. However, data availability and quality are often an issue in many developing countries [20, 26, 29].

For monitoring and evaluation, data need to be collected throughout CSA activities and beyond. However, data collection is difficult and costly, particularly for smallholder farmers [26, 29] and many local institutions.

\subsubsection{Working with Uncertainties}

Assessments of impacts and characterizations of vulnerability (climate impact assessments) are conducted by a variety of models using climatic information as inputs. A long chain of scenarios and models will indicate the potential local impacts of climate change on agriculture and the possible adaptation responses. However, each component of the chain carries its own uncertainties, which may result in a growing number of changes and an expanding envelope of uncertainty [20, 25, 30, 27, 13].

\subsubsection{Attributions of Difficulties}

Climate is flexible by nature. The weather experienced daily is a combined result of natural climate variability and anthropogenic climate change. It is difficult to separate the two for the purposes of assessing the impacts of climate change or monitoring and evaluating the impacts of climate-smart agriculture interventions [29, 25]. It is also not easy to clearly distinguish the effects of many adaptation options from those achieved by broader sectoral development policies $[26,29]$.

It should also be noted that climatic risks are not static. The baseline situation and baseline projections against which impacts of climate-smart agriculture are evaluated may change as climatic conditions change [25, 29]. Frequent updating of a 'moving' baseline with new information on climate, hazards, extreme events, and their impacts on agriculture is necessary to make the appropriate adjustments to climate-smart agriculture interventions and their targets [29, 25, 27].

\subsubsection{Inadequate Capacities for Assessment and Monitoring and Evaluation}

Inadequate capacities (technical, human, institutional) and resources (human and financial) are often cited as barriers to successful assessment, monitoring and evaluation activities [26]. The current trend is to use country-led systems. To make these national systems effective there is a need to strengthen human and institutional capacity through training and capacity development in the area of data collection, assessments, monitoring and evaluation for CSA.

\section{Conclusion}

Activities involved in monitoring and evaluation include setting project baselines, defining indicators, measuring progress, and evaluating successes and the problems encountered by climate-smart agriculture interventions at the end of the project and beyond. There are two major types of assessments for CSA policy and project design: climate impact assessments and CSA options assessments. CSA options assessments can identify the options that will be more effective in achieving CSA objectives.

Monitoring and evaluation are initiated during the project preparation stage of the project cycle and are closely linked with the overall CSA planning. Monitoring tracks progress, checks intermediate results, and informs adjustments during the project implementation. Evaluation deals primarily with the assessment of the results and impacts of CSA interventions. The monitoring and evaluation framework presented in this review has six major elements: situational analysis and forecasting; intervention planning and targeting, and defining detailed indicators; implementation and monitoring; evaluation; monitoring and evaluation as closely related activities; and the importance of learning. The interventions should be designed within a results-based framework with particular emphasis on the development of appropriate indicators.

There are eight irreplaceable challenges for assessment, monitoring and evaluation for CSA: the difficulty of setting the goals and an agreed definition of CSA; the multi-sectoral nature of CSA and the involvement of various stakeholders; Positioning within a broader development perspective; the issues of scale, leakage, permanency, externality and ancillary impact; the difficulty of obtaining quality data and information; the uncertainties with data, information, and methods; difficulty of attribution; and inadequate capacity and resources. Most of the guiding principles for responding 
to these challenges are common to any assessment, monitoring and evaluation activity for climate smart agriculture.

\section{References}

[1] FAO. (2017). Overview: Climate Smart Agriculture Sourcebook. Available at: http://www.fao.org/climate-smart-agriculturesourcebook/enabling-frameworks/module-c9-monitoring-evaluation/c9-overview/en/ (accessed 29 May 2019).

[2] World Bank. (2019). Agriculture, forestry, and fishing, value added (\% of GDP), available at: https://data.worldbank.org/indicator/NV.AGR.TOTL.ZS?name_desc=true (accessed 16 April 2019).

[3] FAO. (2016). Food and Agriculture: Key to achieving the 2030 Agenda for Sustainable Development. Rome. Available at: http://www.fao.org/3/a-i5499e.pdf. (Accessed 16 April2019).

[4] Wiek, A., Withycombe, L., and Redman, C. L. (2011). Key competencies in sustainability: a reference framework for academic program development. Sustainability Science, 6(2), 203-218.

[5] FAO. (2019). Climate Smart Agriculture Sourcebook [WWW Document]. Available at: http://www.fao.org/climate-smartagriculture- sourcebook/en/ (accessed 5.31.19).

[6] CCAFS-CSA Guide website, available at: https://csa.guide/csa/monitoring-evaluation-and-learning(accessed 24 May 2019).

[7] Carter, T. R., Jones, R. N., Lu, X., Bhadwal, S., Conde, C., Mearns, et al. (2007). New assessment methods and the characterization of future conditions. Climate change 2007: impacts, adaptation and vulnerability, by M. L. Parry, O. F. Canziani, J. P. Palutikof, P. J. van der Linden, \& C. E. Hanson (eds.), Contribution of Working Group II to the Fourth Assessment Report of the IPCC. Pp. 133-171. Cambridge University Press, Cambridge, UK.

[8] IPCC. (2012). Managing the risks of extreme events and disasters to advance climate change adaptation, Field, C. B., V. Barros, T. F. Stocker, D. Qin, D. J. Dokken, K. L. Ebi, M. D. Mastrandrea, K. J. Mach, G.-K. Plattner, S. K. Allen, M. Tignor, \& P. M. Midgley (eds.), A Special Report of Working Groups I and II of the IPCC. Cambridge University Press, Cambridge, UK, and New York, USA. P. 582.

[9] Engle, N. L. (2011). Adaptive capacity and its assessment. Global Environmental Change, 21: 647-656.

[10] Walker, B., Holling, C. S., Carpenter, S. R. and Kinzig, A. (2004). Resilience, adaptability and transformability in social-ecological systems. Ecology and Society, 9(2). (Available at http://www.ecologyandsociety.org/vol9/iss2/ art5).

[11] Walker, B., Gunderson, L., Kinzig, A., Folke, C., Carpenter, S., and Schultz, L. (2006). A handful of heuristics and some propositions for understanding resilience in social-ecological systems. Ecology and Society, 11(1). (Available at http://www.ecologyandsociety.org/vol11/iss1/art13/).

[12] Folke, C. (2006). Resilience: the emergence of a perspective for social-ecological systems analyses. Global Environmental Change, 16 (3): 253-267.

[13] German International Development Cooperation (GIZ). (2011). Making adaptation count: concepts and options for monitoring and evaluation of climate change adaptation.

[14] German Technical Cooperation (GTZ). (2009). Climate change information for effective adaptation: a practitioner is manual.

[15] World Bank. (2009). Note 3: assessing climate risk. Guidance Notes Mainstreaming Adaptation to Climate Change in Agriculture and Natural Resources Management Projects. (available at http://climatechange. worldbank.org/content/note-3-assessing-climate-risk)

[16] United Nations Development Programme (UNDP). (2009). Applying climate information for adaptation decision making.

[17] UNDP. (2010). Screening tools and guidelines to mainstream climate change adaptation into development assistance: a stocktaking report.

[18] FAO. (2012). Annex 2: approaches to rapid assessments of impacts of climate variability and climate change on agriculture in the project area. Incorporating climate change considerations into agricultural investment programmes: a guidance document. (Available at http://www.fao.org/docrep/016/i2778e/i2778e.pdf)

[19] International Fund for Agricultural Development (IFAD). (2002). Managing for impact in rural development: a guide for project monitoring and evaluation. (Available at http://www.ifad.org/evaluation/guide/index.htm)

[20] Organization for Economic Cooperation and Development, Development Assistance Committee (OECD DAC). (2009). Policy guidance on integrating climate change adaptation into development co-operation. Joint High-Level Meeting of the OECD DAC and the Environmental Policy Committee (EPOC), OECD. (Available at http://www. oecd.org/document/40/0, 3746, en_2649_34421_42580264_1_1_1_1,00.html).

[21] Brooks, N., Anderson, S., Ayers, J., Burton, I., and Tellam, I. (2011). Tracking adaptation and measuring development. IIED Climate Change Working Paper No. 1.

[22] Brooks, N., Anderson, S., Burton, I., Fisher, S., Rai, N., and Tellam, I. (2013). An operational framework for Tracking, Adaptation and Measuring Development (TAMD). IIED Climate Change Working Paper No. 5.

[23] Global Donor Platform for Rural Development (GDPRD), FAO \& World Bank. (2008). Tracking results in agriculture and rural Herweg, K., development in less-than-ideal conditions: a sourcebook of indicators for monitoring and evaluation. (Avail- 
able at http://www.seachangecop.org/sites/default/files/documents/2009\%2003\%20World\%20Bank\%20-percentage20Mand Epercentage20indicatorspercentage20inpercentage20agriculture.pdf).

[24] Rosenstock, T. S., Lamanna, C., Chesterman, S., Bell, P., Arslan, A., et al. (2016). The scientific basis of climate-smart agriculture: A systematic review protocol. CCAFS Working Paper no. 138. Copenhagen, Denmark: CGIAR Research Program on Climate Change, Agriculture and Food Security (CCAFS).

[25] Hedger, M., Mitchell, T., Leavy, J., Greeley, M., Downie, A., and Horrocks, L. (2008). Desk review: evaluation of adaptation to climate change from a development perspective. Institute of Development Studies.

[26] United Nations Framework Convention on Climate Change (UNFCCC). (2010). Synthesis report on efforts undertaken to monitor and evaluate the implementation of adaptation projects, policies and programmes and the costs and effectiveness of completed projects, policies and programmes, and views on lessons learned, good practices, gaps and needs. Note by the secretariat.

[27] Villanueva, P. S. (2010). Learning to ADAPT monitoring and evaluation approaches in climate change adaptation and disaster risk reduction - challenges, gaps and ways forward. Strengthening Climate Resilience (SCR) Discussion Paper No. 9. SRC. (Available at http://community.eldis.org/.59d49a16/Learning-to-ADAPT.pdf).

[28] FAO. (2012). Using marginal abatement cost curves to realize the economic appraisal of climate-smart agriculture: policy options.

[29] Lamhauge, N., Lanzi, E., and Agrawala, S. (2011). Monitoring and evaluation for adaptation: lessons from development co-operation agencies. OECD Environment Working Paper No. 38. OECD. (Available at http://dx.doi.org/10.1787/5kg20mj6c2bw-en).

[30] World Bank. (2010). Note 8: monitoring and evaluation of adaptation activities. Guidance Notes Mainstreaming Adaptation to Climate Change in Agriculture and Natural Resources Management Projects. Climate Change Team, Environment Department, World Bank. 